This is an electronic reprint of the original article. This reprint may differ from the original in pagination and typographic detail.

Author(s): Salonen, Eija; Laakso, Marja-Leena; Sevón, Eija

Title: $\quad$ Young children in day and night care : negotiating and constructing belonging during daily arrivals

Year: $\quad 2016$

Version:

Please cite the original version:

Salonen, E., Laakso, M.-L., \& Sevón, E. (2016). Young children in day and night care : negotiating and constructing belonging during daily arrivals. Early Child Development and Care, 186(12), 2022-2033. https://doi.org/10.1080/03004430.2016.1146717

All material supplied via JYX is protected by copyright and other intellectual property rights, and duplication or sale of all or part of any of the repository collections is not permitted, except that material may be duplicated by you for your research use or educational purposes in electronic or print form. You must obtain permission for any other use. Electronic or print copies may not be offered, whether for sale or otherwise to anyone who is not an authorised user. 


\title{
Young children in day and night care: negotiating and constructing belonging during daily arrivals
}

\author{
Eija Salonen, Marja-Leena Laakso and Eija Sevón \\ Department of Education, University of Jyvaskyla, Jyvaskyla, Finland
}

Eija Salonen, Corresponding author

Department of Education, University of Jyvaskyla, Jyvaskyla, Finland PO Box 35, 40014 University of Jyvaskyla, Finland p. +358 (0)503670783

email: eija.p.salonen@jyu.fi

Marja-Leena Laakso

Department of Education, University of Jyvaskyla, Jyvaskyla, Finland PO Box 35, 40014 University of Jyvaskyla, Finland

p. +358 (0)40 8054024

email: Marja-leena.laakso@jyu.fi

Eija Sevón

Department of Education, University of Jyvaskyla, Jyvaskyla, Finland PO Box 35, 40014 University of Jyvaskyla, Finland

p. +358 (0)408053650

email: eija.sevon@jyu.fi

This work was supported by the the Academy of Finland under Grant 251410. 


\title{
Young children in day and night care: negotiating and constructing belonging during daily arrivals
}

\author{
The paper aims at understanding the processes related to young children's \\ belonging during daily arrivals at day and night care. Two aspects of a child's \\ belonging are considered: membership and sense of belonging. Data were \\ gathered by ethnographic observation of eight children aged from 20 to 36 \\ months in two Finnish day care centres offering day and night care. Arrival \\ episodes taking place at different times of day were analysed qualitatively based \\ on the children's actions and expressions. During these episodes, the children \\ negotiated and constructed their belonging by interacting with adults, peers and \\ material objects. These interactions took place within varying social and material \\ surroundings and according to different daily routines that sometimes challenged \\ the child's belonging. The results underline the importance of sensitive \\ responsiveness by educators to young children's initiatives in supporting \\ children's belonging during daily arrivals at day and night care.
}

Keywords: young children; belonging; daily arrivals; day and night care; flexible child care

\section{Introduction}

When arriving at day care, children need to negotiate and construct their belonging in the social and material surroundings of the day care centre. This process concerns children's membership as well as their sense of belonging - an experience essential for wellbeing. In the context of day and night care, children arrive at the centre during different times of day from early morning to evening. This implies a great diversity of arrival situations including variation both in the people present at the centre and in the material objects available to the child. As such, children arriving at day and night care have varying resources at their disposal for negotiating and constructing their belonging. This makes daily arrivals at day and night care particularly interesting with respect to young children's wellbeing. Even so, none of the few studies on arrival 
situations focuses on this form of care. In the present study, we contribute to filling this gap by exploring the interactions through which young children negotiate their membership during daily arrivals at day and night care. Furthermore, we offer interpretations of the impact of these interactions on young children's sense of belonging.

\section{Day and night care}

The form of day care in focus in this study, day and night care, responds to the child care needs arising from current working life. Many parents of young children have nonstandard work schedules that may include work during evenings, nights and weekends, sometimes on a varying or irregular basis (Li et al., 2012). Because of this diversity of parental working hours, a form of child care is needed that can be adapted to many kinds of schedules. In Finland, many municipal day care centres offer state-supported day and night care, that is, child care and early education during both standard daytime hours and nonstandard hours, i.e. evenings, nights and weekends. In these centres, children are cared for by trained nurses and kindergarten teachers (henceforth termed educators). Day and night care is available for children in families where nonstandard hours are worked either by both parents or a lone parent. This form of care was attended by 7\% of all the children in municipal day care in Finland in the year 2013 (Säkkinen, 2014). The proportion is likely to grow: according to professionals working in this field there is a need to expand day and night care services (Rönkä et al., 2014).

Day and night care is characterized by flexibility with respect to the individual schedules of families. For parents, this form of care is likely to make it easier to manage the combination of nonstandard work and family life. For children, however, day and night care may mean a less stable daily life. This notion is based on a study by De

Schipper, Tavecchio, Van IJzendoorn and Linting (2003) on so called flexible child 
care, where flexible refers to families' schedules. In this study, more flexible child care was found to be associated with less daily stability in the structure of a child's program and his or her contacts with caregivers and peers. Furthermore, the daily stability of care mattered for the well-being of 6- to 39-month-old children in day care, as an increase in the variety and number of caregivers and peers was associated with less well-being (De Schipper et al., 2003). Although no direct association was found between flexible child care and child wellbeing, these results point to the potential challenge to young children's wellbeing posed by the varying and multiple social contacts characteristic of flexible child care arrangements.

\section{Daily arrivals}

We view daily arrival situations as transitions between two different contexts, home and day care, that coexist in children's daily lives. During these transitions, children need to separate from their primary caregivers and join the people present at the day care centre. They also need to find their places in the material surroundings of the centre. These transitions are accompanied by a switch between two cultures that may differ from each other: the culture of the child's family and the culture of the day care centre (see Andenaes, 2011). The two cultures may entail distinct values, beliefs and practices, as Hughes, Greenhough, Yee and Andrews (2010) have discussed with respect to daily transitions between home and school. These aspects, in turn, have an impact on the roles and options that are open to children in the two contexts of their daily lives (Hughes et al., 2010).

How, then, do young children negotiate such a transition? Only a few studies have addressed this topic. In one of the earliest of these, Field et al. (1984) observed the leave-taking and reunion behaviours of 3- to 69-month-old children and their parents at a nursery school. The differences in the children's and parent's behaviours were found 
to be dependent on the child's age, gender and duration of time in school as well as the parent's gender. The results of the study suggest that both parent and child contribute strongly to the dynamics of interaction during leave-takings and reunions. In a more recent study by Xu (2006), the emotional reactions of 18- to 30-month-old toddlers to separation from their primary caregivers were observed during arrivals at a university pre-school. The toddlers' emotional reactions were found to be related to their parents' or grandparents' and teacher's behaviours as well as to the physical setting of the classroom. According to the study, primary caregivers and teachers have a particularly critical role in supporting children's daily transition to pre-school. On the other hand, in the observation study by Grady, Ale and Morris (2012) on 3- to 5-year-old children, their parents and caregivers, it was suggested that continued parental involvement may hinder children's settling into the pre-school environment during daily drop-off.

This knowledge on arrivals is complemented by Løkken’s (2004) study on greetings and welcomes among toddler peers upon their arrival at day care. The 9- to 30-month-old participants in this study were observed to be attentive and active in greeting their peers. These greetings were of various kinds, including physical closeness and expressions of joy and enthusiasm. Peers, then, can sometimes be in an important position to support a child's transition to day care. This assumption is compatible with the observations by Engdahl (2012) on interaction between young children in a preschool setting. In this study, 14- to 24-month-old children were found to be active in making spontaneous initiatives towards peers. Such initiatives by children were interpreted as moves towards the creation of friendships. The results indicate the importance of peers for young children in their daily life in pre-school.

As far as we know, the earlier studies on daily arrivals have been conducted in centres operating during standard daytime hours. Arrivals at day and night care, then, 
entail characteristics that may not have been present in these earlier studies. As children's arrival times vary from early morning to evening, arrival situations occur during different activities and in different locations in the day care centre. Furthermore, a child's social surroundings will vary according to the individual schedules of the children and personnel. These characteristics make arrivals at day and night care a particularly relevant focus of study.

\section{Belonging}

Here, arrival situations are viewed through the lens of young children's belonging, as this concept helps us to be sensitive to the diverse interactions that shape a child's experience during these brief and fleeting moments of everyday life. In the literature on belonging, the concept of belonging has been represented in several different, often discipline-specific ways. From this multiplicity, two main aspects of belonging can be identified that are relevant for our study on the daily life of young children. First, there is an emotional experience, known as a sense of belonging. Second, there are negotiations of membership that have been termed the politics of belonging (Stratigos, Bradley \& Sumsion, 2014). These negotiations are closely connected to the emotional experience of belonging and can thus be regarded as providing a route to a better understanding of this experience.

The emotional experience of belonging, often termed sense of belonging, has been characterized by many favourable feelings in relation to diverse external referents. These feelings can be grouped into two kinds (see Hagerthy, Lynch-Sauer, Patusky, Bouwsema \& Collier, 1992). First, there are feelings that indicate perceived social support from other people. These include feeling valued, needed and accepted (Hagerthy et al., 1992) as well as feeling cared about, respected and important (Strayhorn, 2012, p. 3). Second, there are feelings that are based on shared, similar or 
compatible characteristics between a person and an external referent that may be social, material or cultural. Such characteristics may evoke a feeling of fitting in (Hagerthy et al., 1992) or a feeling of ease and comfort in one’s surroundings (May, 2013, p. 81). More generally, a sense of belonging can be described as a feeling of being at home, of experiencing safety and comfort (see May, 2013, p. 82). This kind of emotional experience can be regarded as essential to a person's wellbeing. Hagerthy et al. (1992) posit a sense of belonging as a vital element of mental health and social wellbeing. Some theorists even argue that belonging is a basic need (Maslow, 1954) and a fundamental human motivation (Baumeister \& Leary, 1995).

Belonging, however, is not just an experience, but something that is actively done in relation to other people as well as physical places (see Bell, 1999; Miller, 2003; Bennett, 2012, p. 25). According to Stratigos, Bradley and Sumsion (2014), belonging is 'enacted, contested and negotiated in the various times, places and groups in which we live our daily lives'. These daily interactions can be understood as a political process of producing boundaries of membership - boundaries that differentiate between those who belong to a certain community and those who do not (Nagel, 2011, p. 120). Thus, belonging is closely connected to questions of inclusion and exclusion (Yuval-Davis, 2011, p. 18). Moreover, the political processes of belonging include struggles over the meanings of belonging, that is, what is involved in belonging to a certain community (Yuval-Davis, 2011, p. 20).

In the flow of everyday life, belonging is not a static state that can be reached once and for all. Rather, belonging is better understood as transitory and fluid, a phenomenon that varies from situation to situation and from moment to moment (May, 2013, p. 83, 90). Likewise, sense of belonging may not necessarily be experienced completely. Drawing on several analyses of the concept of belonging (Hagerthy, 1992, 
Mahar, 2013, May, 2013), this experience could rather be described as an assortment of feelings that we have more or less during a certain moment, depending on many different aspects of our selves and surroundings. Most of the time, we do not pay much attention to this experience. Disruptions in the everyday environment, however, may awaken a feeling of not belonging (May, 2013, p. 89). Arrivals at day and night care may sometimes produce such a disruption as a child moves into a new, sometimes unpredictable situation. At the very least, arrival situations require children to negotiate and construct their belonging within their changed social and material surroundings.

\section{The study}

In the present study, we aimed at understanding the processes related to young children's belonging during arrivals at day and night care. According to what is currently known about children’s capacities (see Cole, Martin \& Dennis, 2004), even very young children are able to communicate their emotional states and to regulate their emotional environment through a multitude of vocal, facial and bodily expressions. In light of this knowledge, we took children's expressions and actions as a starting point and explored the interactions through which children negotiate and construct their belonging within the social and material surroundings of a day care centre. In doing so, we paid attention to both children's membership and their feelings related to a sense of belonging. Furthermore, we studied the ways educators responded to children's initiatives and thus influenced children's belonging. Specifically, we sought answers to the following two questions regarding young children's daily arrivals at day and night care.

(1) How do children negotiate and construct their belonging in interaction with their surroundings? 
(2) How do educators' responses to children's initiatives influence children's belonging?

\section{Method}

\section{Data collection}

This study is part of an international research project 'Children's socio-emotional wellbeing and daily family life in a 24-h economy (Families 24/7)' and a Finnish substudy on young children's daily life in the day and night care context. The data were collected in two municipal day care centres offering day and night care, that is, child care and early childhood education during both standard daytime hours and nonstandard hours. One of the centres was a day and night care centre open 24 hours, 7 days a week. The other was a day care centre with extended opening hours from 5 am to 10.30 pm from Monday to Friday.

All the parents and educators of children in the (under-three) day care groups were given information about the study, and parental consent for their children's participation was obtained for eight children: four girls and four boys. During the data collection they were aged between 20 and 36 months. All of the children attended care during non-standard care hours. However, they differed from each other in their care schedules: all of them attended evening care, four attended weekend care and two attended night care. One of them had a regular schedule, while for the other seven children the timing of care was more irregular.

The study data comprised ethnographic observations at the two day care centres. Altogether 41 visits were made to the day care centres during the 8-month period from May 2012 to December 2012, each visit lasting from 0.5 to 2.5 hours. Most visits took place during hours specific to day and night care: evenings, nights and weekends. In 
addition, the visits concentrated on arrivals to and departures from care at varying times, as is characteristic of day and night care.

At the beginning of each visit to the day care centres, the time, date, location of events and people present, were noted. The researcher sat near a focus child and took written notes in a running record format without predetermined categories. Special attention was paid to the child's physical acts and vocal, facial and bodily expressions towards his or her social and material surroundings. Furthermore, notice was taken of the interactions within which these expressions and actions took place. In addition to written notes, video recordings were made in some situations. For ethical reasons, video was not used during arrivals. During observations, the researcher was careful not to disturb children's natural activities and the flow of events. However, the observation included researcher-child interaction if the initiative was made by the children. The notes were carefully expanded and transferred to a computer after each visit to the day care centre.

In order to respect the young children's rights to informed and voluntary participation as much as possible, careful attention was paid to the children's reactions towards the researcher and the research procedure during the data collection. All the child participants who showed interest in the researcher and the study were informed verbally about the study. No child was observed or videotaped secretly or against their expressed will.

\section{Data analysis}

For the present study, arrivals at day and night care were identified as critical moments for children's belonging, as they require a child to negotiate the transition from their home environment to that of the day care centre. The observational data included 12 arrival episodes, all of which were chosen for the present analysis. The arrival episodes 
began when a child entered either the yard or the interior of the centre, depending on the ongoing activity at the centre. The episodes ended when three conditions were met: 1) the parent had left for work, 2) the child had started to participate in the ongoing activity, and 3) the child expressed a sense of ease and comfort by vocal and/or bodily expressions or by deep involvement in play. In other words, the episodes ended when a child had successfully gone through the transition from home to day care. If these conditions were not met before bed time, the episode was deemed to have ended when the child fell asleep. The duration of one episode varied from about 5 minutes to 30 minutes.

The 12 arrival episodes were analysed qualitatively by identifying and categorizing the children's initiatives and the educators' responses. To answer the first research question on children's ways of negotiating and constructing their belonging, the analysis first focused on the children's initiatives, i.e. the voluntary physical acts and the vocal, facial and bodily expressions by means of which the children influenced the flow of events around them. The initiatives included not only contributing to the situation, but also resisting and avoiding something or someone, as well as actively refraining from action. These initiatives were regarded as the children's ways of negotiating and constructing their belonging. The initiatives were analysed within the chains of interactions of which they formed part. Based on the target of an initiative and the child's expressions of emotion during the chain of interaction, the initiatives were grouped into three main categories of negotiating and constructing belonging: 1) interacting with adults, 2) interacting with peers and 3) interacting with material objects.

To answer the second research question, the analyses of the arrival episodes focused on the educators' responses to the children's initiatives. These responses included verbal expressions and physical actions that were initiated by the children's 
actions or expressions, such as talking or crying. First, the responses during each arrival episode were identified. All these responses were then explored for their influences on the manifestations of children's belonging: their membership in the day care context and expressions of emotion related to their sense of belonging. Two categories of responses were identified that influenced the children's belonging in two opposite ways: 1) respecting a child's initiative and 2) disregarding a child's initiative.

\section{Findings}

\section{Young children's ways of negotiating and constructing their belonging}

During the arrival episodes, the young children influenced the flow of events through their own initiatives- that is, through physical actions, gestures and vocal expressions directed towards other people and material objects. These initiatives can be seen as children's ways of negotiating and constructing their belonging, understood as their membership within the social and material surroundings of the day care centre. The initiatives can also be interpreted as the children's attempts to construct feelings related to a sense of belonging, such as feelings of safety, ease and comfort within their surroundings. Three main categories of initiatives functioning in these two ways were identified.

\section{Interacting with adults}

All the arrival episodes included child initiatives towards an adult: the mother, an educator or sometimes the researcher. These initiatives were various. The children communicated with gestures, crying and verbal expressions in which they expressed their will, shared ideas and asked questions about the day's events and the people present at the centre. The children also approached the adults physically: they came up 
close to them, hugged them, nestled against them and climbed into their laps. The adults typically responded to these initiatives by verbalizing the situation and physically bringing the children close to them.

In the following example, taken from the arrival of Mason (29 months), he is interacting with his mother after arriving at the lobby of the day care centre at $11.40 \mathrm{am}$, just before nap time. This short chain of interaction takes place in the presence of Annie, an educator familiar to Mason.

\footnotetext{
Mason cries a little and several times says 'Mummy’s lap', with sadness and anxiety in his voice. His mother takes him into her lap. She carries him to the toilet and helps him wash his hands, still holding him in her lap. ... She explains to Mason 'Mummy's going to work, daddy will come and pick you up later'. The mother hands Mason into Annie’s lap. Mason’s eyes look tired, but he’s no longer crying. His mother says ‘Bye-bye' and leaves.
}

In this example, Mason makes initiatives towards his mother: he cries and asks her to take him into her lap. Mason’s crying, his tone of voice and the repeated requests to be taken into his mother's lap suggest that he is not feeling good about the arrival situation - rather, these expressions reveal feelings of sadness and anxiety. His mother, for her part, holds Mason in her lap and helps him to get ready for a nap. She also talks to Mason about her going to work and his father coming to pick him up. Upon leaving the centre, she gives Mason to Annie, who holds him in her lap. The actions of his mother and Annie help Mason to feel better, as he has stopped crying by the end of the interaction.

Viewed through the lens of belonging, this short chain of interaction can be seen as a negotiation by Mason of his belonging to the two contexts of his daily life, home and day care. The interaction between his mother and Mason confirms Mason's membership in the family group before his temporary separation from his mother. In 
addition, this interaction promotes Mason's membership of the ongoing activity at the day care centre, as she assists him with the routines of nap time. The emotional content of the interaction - Mason's expressions of sadness and anxiety upon arriving at day care - can be interpreted as manifestations of the feeling of not belonging. Mason's initiatives towards his mother, then, can be seen as his effort to obtain relief from this uncomfortable feeling and enhance his sense of belonging. Based on Mason's emotional expressions, his mother's response- taking him into her lap as he wishes - alleviates the uncomfortable feeling. This kind of response is likely to support Mason's experiences of feeling valued and cared about as well as feeling safe and comfortable - feelings that are highly compatible with a sense of belonging.

Many other interactions between the children and adults resemble the above example. By their initiatives, the children usually sought attention and assistance from the adults. The adults most often responded by verbal and physical assistance that helped the children to join in the ongoing situation and keep abreast of the flow of events. By assisting the children, the adults also defined what membership in the day care group entailed and required from the child. Turning to the children's emotional experiences, physical closeness to familiar adults seemed to enhance feelings related to a sense of belonging. The importance of physical closeness was most obvious when a child expressed feeling scared or upset by crying or tensing up. In these situations, the physical closeness of a familiar adult caused the child calm down and relax.

Not any adult, however, but particularly the adults with whom the children already feel familiar and safe evoked interactions supportive of a young child's sense of belonging. When the children met adults unfamiliar to them, their reactions sometimes were quite the opposite: they expressed feelings of unease or fear by tensing body or by crying. This was the case when Emma (20 months) arrived at the centre at $11.00 \mathrm{am:}$ 
'Emma looks directly at an educator unfamiliar to her and starts to cry’. Interaction with adults, then, had a potential for both enhancing and threatening a child's sense of belonging, depending on the familiarity of the adult in question. This presents a potential challenge for children attending day and night care: due to the individual schedules of children and educators, the educator most familiar to a child was not always present upon the child's arrival. This applied in particular to children who attended the centre that was open 24 hours, 7 days a week.

\section{Interacting with peers}

In five episodes, a child contributed actively to interaction with a peer or peers. These initiatives included physical action: walking or running over to a peer and following a peer into another room. In addition, the initiatives included verbal communication: calling a peer's name and talking to him or her. In these situations, the peers shared the interest in mutual interaction.

In the following example, William (36 months) has arrived at the day care centre with his mother. It is $11.30 \mathrm{am}$, just before nap time. He has first employed resistance initiatives, such as lagging behind the entry door and shaking his head when asked to come in. However, his expressions change when he meets his friend Henry.

\footnotetext{
William’s friend Henry comes to the lobby, smiling brightly at William. On seeing Henry, William, too, smiles brightly and says ‘Henry, Henry, Henry, look, I’ve got sunglasses'. William sheds his outdoor clothes and says again and again 'Henry, Henry'. Henry comes over to William. An educator who has come to the lobby tells me that William and Henry are best friends.
}

William makes several initiatives towards Henry: he calls Henry's name and talks to him about the sunglasses. Henry, in turn, comes close to William. Both of the boys are smiling, as if they felt happy together. William also appears to be enthusiastic as he 
calls Henry’s name repeatedly. From the perspective of belonging, William’s interaction with Henry can be interpreted as his way of negotiating and constructing his membership in his day care group by joining Henry. Based on William’s emotional expressions of joy and enthusiasm, the interaction with Henry also supports his sense of belonging.

Like the interaction between William and Henry, all the mutual interactions between a child and a peer were characterized by joy and enthusiasm that the children expressed by happy facial expressions and a cheerful tone of voice. In some cases, as in the previous example, interaction with a peer was associated with marked changes in a child's actions and expressions: passivity and resistance turned to eager participation. Altogether, joining a peer or peers can be interpreted as an initiative that supports a child's membership in the social group as well as the related emotional experience of belonging.

Again, it is noteworthy that it was not just any child but familiar peers and a good friend, in particular, who evoked such cheerful interaction. Due to the individual schedules characteristic of day and night care, however, a best friend was not necessarily present at the centre upon a child's arrival. Instead, the children occasionally met children less familiar to them. In such situations, they sometimes attempted to avoid interaction, as is the case in another episode when William (36 months) arrives at 7.00 pm: 'William notices a group of older girls passing by the lobby and covers his face with hands'. With this gesture, William shows that he is not a member of this group of children. Meeting peers, then, could be associated with very different initiatives, avoidant as well as constructive, depending on the quality of the relationship between a child and the peers he or she met. Correspondingly, the influence of peers on the children's emotional experiences varied. 
A further challenge relating to peer interaction was identified. The children sometimes arrived at the centre just before bedtime. At these times, peer interaction was simply not appropriate to the ongoing routine. This is the case in the following example featuring Mason (29 months), his peer James and Annie, an educator. After arriving at the centre with his mother at $11.40 \mathrm{am}$, Mason has been carried to the dormitory, where several children are already in their beds because it is nap time. 'Mason moves around in his bed and talks to one of his peers: “James, James”. Annie tells Mason to put his head on his pillow and comes between the boys to help them to fall asleep.' As can be seen here, interaction between familiar peers, although a potential source of belonging for a child, conflicted with the routine of sleep.

\section{Interacting with material objects}

When arriving at day care, the children interacted not only with other people but also with material objects. During seven of the arrival episodes, the children contributed to the flow of events with initiatives of this kind. They explored and played with many kinds of objects both indoors and outdoors: toys, clothes, clothes baskets, water bottles, bikes, slides, sand and stones. With only a few exceptions, these initiatives matched the children's material surroundings and the ongoing activity at the centre.

In the following example, Daniel (31 months) arrives at the yard of the day care centre with his mother at $10.30 \mathrm{am}$, during free play outdoors. There are several educators and plenty of children at different locations around the yard. Because of the hot weather, the children are allowed to drink water from their own bottles placed on a table in the yard.

\footnotetext{
Daniel comes running into the yard, his mother walking behind him. Daniel looks cheerful and relaxed. He goes over to his own bottle and drinks. ... Daniel comes
} 
up to his mother once more and then runs to play with the material objects in the yard.

During this arrival situation, Daniel makes many initiatives towards the material surroundings and objects in the yard: he comes running to the yard, takes a water bottle, drinks water and runs to the yard to play. During this interaction Daniel expresses feelings of ease and comfort, both via his cheerful facial expressions and his easy-going and energetic actions. Based on Daniel's actions and expressions, the familiar and inspiring material objects in the day care yard help him to join in the free play outdoors. In terms of belonging, these material surroundings help Daniel to construct his membership in the day care context and maintain feelings that are compatible with a sense of belonging.

The example furnished by Daniel demonstrates the typical role of their material surroundings for those children who made initiatives towards material objects or places. These children constructed their belonging in the context of day care through exploring and playing with material objects that they found pleasing and meaningful. The children's initiatives towards material objects were usually accompanied by cheerful and enthusiastic action or deep involvement in play. These bodily expressions can be interpreted as manifestations of feelings of ease and comfort or a feeling of fitting in.

In a few cases, a child resisted the expected interaction with the material context. In one example of this kind, William (36 months) arrives at the centre with his mother at $10.30 \mathrm{am}$, when the other children are having a lesson. William talks to his mother about playing in the yard, but staying outdoors is not compatible with the ongoing activity inside. He then resists entering the day care by the front door: 'William stays in the doorway, peeks behind the glass door and shakes his head when his mother asks him to come in'. Such challenges, however, were rare in the present data. Instead, the 
material surroundings of the day care centre often helped the children to construct their belonging - both as membership and as sense of belonging.

\section{Influence of educators' responses on young children's belonging}

The educators responded in many ways to the children's initiatives while carrying out the daily routines of the day care centre, such as the routines associated with having lunch or napping/sleeping. These responses - both verbal and physical - reflect the pedagogical culture of the day care centre as well as the resources available to educators in their work. Two kinds of responses were identified that influenced the children's belonging in opposite ways.

\section{Respecting a child's initiative}

When carrying out their daily routines, the educators usually had the possibility to pay sensitive attention to the initiatives of a child arriving at the centre. They responded to a child's initiatives in many ways that respected the child's expressed needs. These responses included providing physical closeness and assistance, verbalizing the situation, offering the child choices and supporting interaction between the child and familiar peers.

All these responses are contained in the following example drawn from an arrival episode featuring Emma (20 months). She has arrived at the day care centre with her mother at $11.00 \mathrm{am}$. Several children are having lunch, along with two educators, one of whom, Mary, is familiar to Emma.

\footnotetext{
Emma starts crying. ... Mary lifts Emma into her lap and talks to Emma, who calms down and stops crying. Mary holds Emma in her lap while carrying out the lunchtime routines. She gives Emma a choice of where to sit, and Emma chooses Mary's table. Mary asks Emma about her journey to the centre 'Did you come by bike, did you come by car?' and talks to Santtu, a boy sitting at the same table
} 
'Emma's joined us'. Emma eats and smiles a little at Santtu, then watches the teachers who are talking to each other. Most of the time Emma looks serious and tired, but she's not crying anymore.

In this example, Mary recognizes Emma’s crying and responds by supporting Emma's belonging in many ways while carrying out the lunchtime routines. She contributes to Emma's membership by supporting her participation in the ongoing day care activity and the social group present. By responding sensitively to Emma's expressed needs of support, Mary is also likely to enhance Emma's sense of belonging through the related experiences of feeling safe, cared for, valued and important. Emma's calming down can be interpreted as indicating that Mary's responses make her feel better.

What is pivotal in the previous example is the sensitive way Mary relates to

Emma. Her responses bring flexibility to the ongoing daily routine, while not leading to its abandonment. This is also the case with Mason (29 months) on his arrival at nap time. The interaction involving Mason, his peer Aidan and an educator Susan takes place in the dormitory: 'In his bed, Mason talks to Aidan, and Susan says “Yes, Aidan’s here too, you can play together after your nap”'. In making this this comment, Susan shows that she understands Mason's wish to interact with Aidan. Instead of just telling Mason to go to sleep, she explains that playing with a friend will be possible after their nap. This response shows respect for Mason's initiative without interrupting the daily routine. It is likely to make Mason feel that he is an accepted and respected member of his day care group.

\section{Disregarding a child's initiative}

It was rare for the present educators to disregard a child's initiative. However, the few situations of this kind that occurred are important for the study as they add to understanding of the possible influences of educators' responses. These situations took 
place in the dormitory, where children's initiatives were not appropriate to the ongoing activity, that is, settling down to sleep. Instead of showing understanding of a child's feelings or sensitively explaining the situation to the child, educators centred on carrying out their routines.

In the following example, William (35 months) has arrived at the day care centre with his mother at $8.05 \mathrm{pm}$, when other children in night care are already in the dormitory. He has started crying when being separated from his mother. Linda, an educator, has carried him to the dormitory, where several children are in their beds in the company of Carol, also an educator.

In the dormitory William continues crying and moaning. He calms down for a little while, then starts crying again. At the same time Carol is reading aloud a good night story. Linda stays by William's bed. Carol tells William that his crying is disturbing the other children who are listening to the story. William's crying takes on irritable tone. Carol and Linda decide that Linda's presence is not helping William, and Linda leaves the room. William carries on crying. At times he cries irritably, at times he calms down somewhat. At 20.25 pm the crying stops and William seems to have fallen asleep.

Regardless of William's expressions of sadness and irritability, the educators in this example centre on carrying out the routines of settling the children to sleep. By accusing William of disturbing other children, Carol defines the requirements for membership in this group of children: being quiet and listening to the story. William contests these requirements by crying even more irritably. This response is informative about the child's feelings of not belonging, which are likely to be exacerbated as William's initiatives are further disregarded.

\section{Discussion}

Day and night care is commonly attended by Finnish children whose parents work 
nonstandard hours, yet very little is known about children's daily life in day and night care. The aim of this study was to contribute to this knowledge by enhancing understanding on the processes related to young children's belonging - in terms of membership in the day care context and sense of belonging - during their arrivals at the centre. Children's ways of negotiating and constructing their belonging by interacting with their social and material surroundings were explored, as were the influences of educators' responses on children’s belonging.

During arrivals at day and night care, the children in this study actively contributed to interaction with familiar adults, familiar peers and inspiring material objects. These interactions supported their membership in the day care context and enhanced their feelings of safety, ease and comfort - feelings that can be regarded as components of a sense of belonging. The results are in line with the earlier study by $\mathrm{Xu}$ (2006), which demonstrated the important role of primary caregivers and teachers as well as the physical setting of the classroom in supporting children's daily transition to pre-school. The results are also in accordance with the observations by Løkken (2004) on the importance of peer greetings upon a young child's arrival at day care, as well as the findings by Engdahl (2012) on the significance of friendships for young children in pre-school.

Due to the varying times of arrival, however, the arrivals took place in diverse social and material surroundings and during many different activities. This variability corresponds to the findings of De Schipper et al. (2003) on the association between more flexible child care and less daily stability with respect to a child's programme and his or her social contacts. In this context, the presence of the potential sources of belonging varied, sometimes unpredictably. Furthermore, the children's possibilities to 
negotiate and construct their belonging through interaction varied depending on the ongoing activity and the related daily routines.

In challenging situations, the educators were in a crucial position to support the children's belonging. When carrying out their daily routines, the educators most often recognized a child's initiatives and responded in several ways that respected the child's expressed needs: providing physical closeness and assistance, verbalizing the situation, offering choices and supporting interaction between the child and familiar peers. These responses helped the child to join the ongoing activity and the social group, and thus supported the child's membership. Furthermore, sensitive responsiveness on the part of the educators to a child's initiative was likely to enhance the child's sense of belonging through the related experiences of feeling cared about and valued. In this way, the educators contributed to the wellbeing of the children during their daily arrivals at the day and night care centre. We thus see the findings of this study as having two pedagogical implications: in relating to a young child arriving at day and night care, educators can support the child's wellbeing by 1) paying sensitive attention to initiatives made by the child and 2) responding in a way respectful of those initiatives.

The study findings, however, must be considered in the light of two main limitations. First, the number of arrival episodes was very small and thus the findings should be interpreted with caution. Second, the ethnographic observations made by the researcher, although carried out with sensitivity to many aspects of the arrival situations, can give only an incomplete picture of those situations. Due to these limitations, we attained only a partial understanding of the complex and eclectic phenomenon in focus. To obtain more detailed knowledge on the interactions related to young children's belonging and on the challenges and resources associated with arrivals at day and night care, more research is needed. 
Nevertheless, this study, as a preliminary attempt to identify the processes related to young children's belonging in the context of day and night care, yielded some important insights into daily arrivals. By sensitively monitoring children’s expressions and actions towards their social and material surroundings, we shed light on the interactions through which young children's belonging is negotiated, constructed - and sometimes contested - upon their arrival at day care. The findings highlight the importance of the presence of familiar people for children's belonging and the potential challenges associated with varying social surroundings in day and night care. They also reveal the many resources that educators have for sensitively responding to children's initiatives and thereby supporting their belonging. These findings may contribute, for their part, to a better understanding of young children's experiences in day and night care.

\section{Acknowledgements}

We would like to thank the children who participated in this study as well as their parents and educators. We are also grateful to the two day care centres that opened their doors for the purposes of this research. Furthermore, we thank Adjunct professor Niina Rutanen for many inspiring conversations concerning the conceptual framework and the data analysis of the study.

\section{References}

Andenaes, A. (2011). Chains of care: Organising everyday life of young children attending day care. Nordic Psychology, 63(2), 49-67. doi:10.1027/19012276/a000032

Baumeister, R. F., \& Leary, M. R. (1995). The need to belong: Desire for interpersonal attachments as a fundamental human motivation. Psychological Bulletin, 117, 497-529. doi:10.1037/0033-2909.117.3.497

Bell, V. (1999). Performativity and belonging: An introduction. Theory, Culture \& Society, 16(2), 1-10. doi:10.1177/02632769922050511 
Bennett, J. (2012). Doing belonging: A sociological study of belonging in place as the outcome of social practices (Unpublished doctoral dissertation). The University of Manchester, Manchester, UK.

Cole, P., Martin, S., \& Dennis, T. (2004). Emotion regulation as scientific construct: Methodological challenges and directions for child development research. Child Development, 75, 317-333. doi: 10.1111/j.1467-8624.2004.00673.x

De Schipper, J. C., Tavecchio, L., Van IJzendoorn, M., \& Linting, M. (2003). The relation of flexible child care to quality of center day care and children's socioemotional functioning: A survey and observational study. Infant Behavior \& Development, 26, 300-325. doi:10.1016/S0163-6383(03)00033-X

Engdahl, I. (2012). Doing friendship during the second year of life in a Swedish preschool. European Early Childhood Education Research Journal, 20, 83-98. doi:10.1080/1350293X.2012.650013

Field, T., Gewirtz, J., Cohen, D, Garcia, R., Greenberg, R., \& Collins, K. (1984). Leavetakings and reunions of infants, toddlers, preschoolers and their parents. Child Development, 55, 628-653. doi:10.2307/1129974

Grady, J., Ale, C., \& Morris, T. (2012). A naturalistic observation of social behaviours during preschool drop-off. Early Child Development and Care, 182, 1683-1694. doi:10.1080/03004430.2011.649266

Hagerthy, B. M., Lynch-Sauer, J., Patusky, K. L., Bouwsema, M., \& Collier, P. (1992). Sense of belonging: A vital mental health concept. Archives of Psychiatric Nursing, 6, 172-177. doi:10.1016/0883-9417(92)90028-H

Hughes, M., Greenhough, P., Yee, W. C., \& Andrews, J. (2010). The daily transition between home and school. In K. Ecclestone, G. Biesta, \& M. Hughes (Eds.), Transitions and learning through the lifecourse (pp. 16-31). Oxon: Routledge.

Li, J., Johnson, S. E., Han, W.-J., Andrews, S., Kendall, G., Strazdins, L., \& Dockery, A. (2014). Parents' nonstandard work and child wellbeing: A critical review of the existing literature. Journal of Primary Prevention, 35, 53-73. doi:10.1007/s10935-013-0318-z

Løkken, G. (2004). Greetings and welcomes among toddler peers in a Norwegian barnehage. International Journal of Early Childhood, 36(2), 43-58. doi:10.1007/BF03168199

Mahar, A. L., Cobigo, V., \& Stuart, H. (2013). Conceptualizing belonging. Disability and Rehabilitation, 35, 1026-1032. doi:10.3109/09638288.2012.717584 
Maslow, A. (1954). Motivation and personality. New York, NY: Harper \& Row.

May, V. (2013). Connecting self to society: Belonging in a changing world.

Basingstoke: Palgrave Macmillan.

Miller, L. (2003). Belonging to country: A philosophical anthropology. Journal of Australian Studies, 27(76), 215-223. doi:10.1080/14443050309387839

Nagel, C. (2011). Belonging. In V. J. Del Casino Jr., M. E. Thomas, P. Cloke, \& R. Panelli (Eds.), A companion to social geography (pp. 108-124). West Sussex: Wiley-Blackwell.

Rönkä, A., Laakso, M.-L., Tammelin, M., Metsäpelto, R.-L., Sevón, E., Turja, L., \& Poikonen, P.-L. (2014). Aikuisten työ rytmittää lasten arjen [The work of adults schedules the daily life of children]. Hyvinvointikatsaus, 25(1), 36-43.

Stratigos, T., Bradley, B., \& Sumsion, J. (2014). Infants, family day care and the politics of belonging. International Journal of Early Childhood, 46, 171-186. doi:10.1007/s13158-014-0110-0

Strayhorn, T. L. (2012). College students' sense of belonging: A key to educational success for all students. New York, NY: Routledge.

Säkkinen, S. (2014). Lasten päivähoito 2013 - Kuntakyselyn osaraportti [Day care 2013 - A report on a municipal questionnaire]. Retrieved from http://urn.fi/URN:NBN:fi-fe2014061729292

Xu, Y. (2006). Toddlers' emotional reactions to separation from their primary caregiver: Successful home-school transition. Early Child Development and Care, 176, 661-674. doi:10.1080/03004430500147581

Yuval-Davis, N. (2011). The politics of belonging: Intersectional contestations. London: Sage. 